\title{
LA VIDA COTIDIANA EN UN SEMINARIO ESPAÑOL DEL BARROCO: SAN FULGENCIO DE MURCIA (1592-1700)
}

\author{
Cayetano MAS GALVAÑ. \\ Universidad de Alicante.
}

OBSERVACIONES PRELIMINARES.

La aproximación a lo que pudiéramos considerar vida cotidiana en los Seminarios españoles de la Edad Moderna presenta peculiaridades en relación con otros centros de enseñanza. La más notable creemos que se deriva del doble carácter que presentan como instituciones en las que, junto a la mera impartición de enseñanzas de rango medio y superior, viene a superponerse otra fínalidad, entendida como prioritaria desde el propio decreto del Concilio de Trento ${ }^{1}$ que les servía de piedra angular: la de crear unas instituciones que, preservando los jóvenes aspirantes al sacerdocio de los vicios del mundo, sirviesen para formarles en las virtudes más puramente eclesiásticas, en la vida de piedad y religión. Por eso, y al contrario de lo que podía ocurrir en las Universidades (donde la ordenación gubernativa, académica y docente ocupa el primer plano), no es de extrañar el lugar relativamente secundario que se concede -desde el propio decreto conciliar- al contenido específico de las enseñanzas: el eje central de la vida diaria en el Seminario habría de girar en torno al aprendizaje, dentro de un marco de apartamiento del siglo, de los patrones morales y piadosos que se estimaban propios del futuro sacerdote católico. $Y$ eso no se conseguía, obviamente, con sólo impartir determinados contenidos librescos, sino a través de la imitación e interiorización de toda una disciplina de vida; interiorización tanto más profunda cuanto que habría de asegurar la perseverancia en el seguimiento de esos patrones, para el resto de su existencia, por parte de los educandos.

Por lo que al presente estudio, y a sus límites y posibilidades se refiere, este hecho tiene una gran relevancia: las Constituciones de cada Seminario se detienen siempre en ordenar y regular todo lo referente a la vida cotidiana de sus individuos, y ello con un grado de extensión y minuciosidad más difícil de hallar en otras instituciones educativas de su mismo

1 Sesión 23, decreto de reforma, canon 18, 15 de julio de 1563. 
rango. Y no sólo esto es así, sino que -como tendremos ocasión de observar-, también es muy alto, en la vida diaria, el grado de cumplimiento de lo dispuesto en dichas Constituciones. En consecuencia resulta, más que inexcusable, muy deseable, recurrir a ese tipo de textos en cualquier trabajo como el presente, y así lo haremos. No se nos escapa, por otra parte, que la existencia de reglas siempre lleva aparejado su incumplimiento. Desde distinto punto de vista, podríamos decir que las normas sirven de referente para medir el grado de desviación sobre los modelos propuestos como paradigmas de comportamiento. Ciertamente, poseemos (y no sería difícil de hallar más en los archivos) documentos suficientes para nutrir un buen dossier acerca de estos incumplimientos. Sin embargo, es la propia naturaleza de estas últimas fuentes la que se nos impone, y en un sentido que nos lleva a minorar su significación. En primer lugar, en su mayoría se trata de documentos que pertenecen al siglo $\mathrm{XVIII}^{2}$, y por tanto rebasan el marco que aquí nos hemos impuesto. Pero en segundo lugar, más podrían llevarnos a acumular una sucesión de anécdotas -incluso muy voluminosa- que a poder poner en tela de juicio la aplicación de lo dispuesto en las Constituciones, y menos aún en el sentido de abonar un incumplimiento sistemático y generalizado de las mismas. Muy al contrario, la existencia de esas desviaciones, por llamativas que resulten, amén de estar ya prevista en las Constituciones, no debe hacernos olvidar la realidad del día a día: en este sentido, resulta casi obvio insistir en el hecho de que la observancia de las Constituciones es, siempre, la regla dominante.

Hechas estas salvedades, nos resta precisar los objetivos concretos del presente trabajo. Una primera elección nos ha hecho circunscribirnos al siglo XVII, aunque la documentación sea -como se ha dicho- mucho más abundante e incluso más colorista para el siglo XVIII. Y ello por una doble razón. En primer lugar, por una mera cuestión de extensión, pues abordando ambas centurias, rebasaríamos con mucho la propia de un artículo a menos que perdiésemos en la necesaria profundidad: por lo demás, la bibliografía publicada acerca de los Seminarios del Setecientos es lo bastante amplia como para que cualquier interesado pueda hacerse sin mayores dificultades una inteligencia suficiente sobre este tipo de cuestiones $^{3}$. Por el contrario -tal sería la segunda de nuestras razones-, mucho mayor es el vacío en nuestros conocimientos acerca de los Seminarios del Seiscientos. Laguna ésta tanto más importante en la medida que -a nuestro juicio- el modelo de Seminario que se impuso durante el siglo XVII perduró en lo esencial durante la siguiente centuria.

2 El fondo más importante (amén de los que puedan existir en archivos locales, provinciales y diocesanos) se halla perfectamente catalogado en el Archivo Histórico Nacional, sección Consejos.

3 Vid. los trabajos de Francisco MARTIN HERNANDEZ, "La formación del clero en los siglos XVII y XVIII", Historia de la Iglesia en España, Madrid, B.A.C., 1979, tomo IV, pp. 523-582; Francisco y José MARTIN HERNANDEZ, Los Seminarios españoles en la época de la llustración. Ensayo de una pedagogía eclesiástica en el siglo XVIII, Madrid, C.S.I.C., 1973; Arturo MORGADO GARCIA, "Los alumnos del Seminario de San Bartolomé (Cádiz): 1589-1849", Gades, n² 18, 1988, pp. 29-46; id., "La reforma del Seminario de San Bartolomé (Cádiz) en el siglo XVIII", Anales de la Universidad de Cádiz, n" V-VI, 19881989, pp. 279-296; Margarita TORREMOCHA HERNANDEZ, "La formación del clero. El plan de estudios del Seminario Conciliar de San José de Palencia de 1779", Actas del II Congreso de Historia de Palencia, Palencia, 1990, pp. 395-410; José Antonio INFANTES FLORIDO, Un Seminario de su siglo: entre la Inquisición y las Luces, Las Palmas, 1977. Y mis propios trabajos sobre el Seminario de San Fulgencio citados en el curso de este artículo (vid. nota 5). 
De hecho, los datos publicados acerca de los Seminarios del Seiscientos se hallan casi exclusivamente en la obra monográfica que en torno a los mismos publicó F. Martín Hernández hace ya algunos años ${ }^{4}$. La riqueza de la documentación que aporta este autor es incontrastable, pero tratada desde una óptica nacional y, por tanto, amplia y de intención generalizadora. Esto ha determinado una segunda elección por nuestra parte: ante una revisión de los datos exhumados por Martín Hernández, o la profundización en el detalle de un caso concreto, hemos optado por lo último. El caso elegido, en definitiva, ha sido el del Seminario de San Fulgencio de Murcia, cuya trayectoria durante el siglo XVIII hemos estudiado en anteriores publicaciones ${ }^{5}$.

En torno a la trayectoria de este Seminario durante el Seiscientos, poseemos un volumen de información que, sin ser excesivo, cubre los aspectos esenciales a tener en cuenta en una aproximación a la vida cotidiana de sus individuos. Esta documentación consiste básicamente en:

A. Las Constituciones originales, publicadas en el año $1600^{6}$.

B. Copia impresa de los Autos de fundación del Seminario, que cubren el período 1592$1600^{7}$.

C. La contabilidad íntegra de la institución entre los años 1661-1662/1671-16728.

Mientras que el primer documento aporta las normas que debían regir la vida de la institución, el tercero indica de forma muy precisa el grado de su cumplimiento cotidiano. El segundo documento -en fin-, participa de los dos niveles anteriores.

4 Francisco MARTIN HERNANDEZ, Los Seminarios españoles. Historia y pedagogía, 1, (1563-1700), Salamanca, 1963. Como indica el título, la obra se ciñe a los tiempos inmediatamente postridentinos y al siglo XVII, mientras que los Seminarios del Setecientos han sido abordados por el mismo autor en otros trabajos de posterior publicación, ya citados (vid. nota 3).

5 Cf. C. MAS GALVAÑ, "De la Ilustración al Liberalismo: el Seminario de San Fulgencio de Murcia (1774-1823)", Trienio,12, noviembre 1988, pp. 102-175, en donde referimos la bibliografía básica sobre este Seminario.

6 Otorgadas por D. Sancho Dávila y Toledo, obispo fundador, e impresas en el año 1600. Constituciones del Collegio Seminario de S. Fulgencio, fundado en la Ciudad de Murcia, por el Señor Don Sancho de Avila y Toledo, Obispo de Cartagena, y del Consejo del Rey nuestro Señor. Con licencia, Impressas en Murcia en casa de Diego de la Torre, Año de 1600.32 pp. en $8^{\circ}$. Archivo Diocesano de Granada, sig. 230-V, pieza 12.

7 "Copia, bien, y fielmente sacada, de otra, que se sacó de los autos originales, que se principiaron el año de 1592. Por el Ilmo. Señor D. Sancho Dávila y Toledo, obispo que fue de Carthagena, para la fundación, y erección del Colegio Seminario del Señor San Fulgencio de esta Ciudad de Murcia", en Diferentes instrumentos, bulas y documentos pertenecientes a la Dignidad episcopal, impresos de orden del llmo. Sr. D. Diego de Roxas y Contreras, Madrid, 1756. Existen ejemplares tanto en la Biblioteca Nacional de Madrid como en el Archivo Municipal de Murcia. Las referencias que hemos aprovechado en el presente artículo se hallan entre los folios 81 recto y 115 vuelto.

8 Archivo Catedral de Murcia, legajo $79, n^{\circ} 20$. Falta la documentación correspondiente al ejercicio 1662-1663. Por lo tanto, se trata de un total de 10 ejercicios contables, comprendiendo cada uno los papeles del cargo del año anterior (los ingresos recibidos por el administrador) y la data del presente (el gasto efectuado). Así, por ejemplo, al referimos al ejercicio de 1661-1662, se trata del cargo de 1661 y la data de 1662. Dado que la mayoría de estos papeles presentan falta o confusiones en su foliación, habitualmente nos limitaremos a indicar su fecha en el texto cuando los citemos. 
Sobre esta base, hemos ido elaborado un esquema ceñido a los aspectos que consideramos más relevantes para un intento de reconstrucción de la vida cotiana en el Seminario. Este esquema comprende los siguientes apartados:

\section{-Dependencia gubernativa: el control capitular.}

-Gobierno interno: el rector.

-Los colegiales: admisión y procedencia; vestido y alimentación; vida cotidiana; oficios internos y fámulos.

\section{(8) Cont.}

Estas cuentas nos permiten seguir muy detalladamente el origen y gasto de las rentas del Seminario. En primer lugar, observamos que se ha pasado del anterior arrendamiento-de cuya existencia tenemos noticias indirectas- a la administración directa. El periodo coincide con una casi total indiferencia episcopal en materia de Seminario, hallándose ocupado el cargo por un personaje tan problemático como era $D$. Mateo de Sagade. Colegial del Mayor de Santa Cruz y arzobispo de Méjico, sus enfrentamientos con la Audiencia y el virrey hicieron que se le trasladase a Murcia. Una vez allí, hubo de recurrise a métodos violentos para forzarle a residir; tuvo violentos choques con los dos cabildos civil y eclesiástico, dió pocas limosnas y vendió el vino y el trigo procedentes de los diezmos a precios excesivos. El Consejo le impuso una multa de 4.000 ducados e incluso la Cámara propuso que se le trasladase o que el Papa le obligase a renunciar. La muerte de Sagade en 1672 evitó el bochorno (Apud. Antonio DOMINGUEZ ORTIZ, Las clases privilegiadas en la España del Antiguo Régimen, Madrid, 1973, pp.237-238).

Los ingresos que recibía el Seminario procedían exclusivamente de los 3 beneficios que tenía anexados en Almansa, Chinchilla y Las Peñas de San Pedro, constituidos en su integridad por porciones decimales. Bien en dinero (si los administradores de cada uno de los beneficios procedían a su venta in situ), bien en especie (si los remitían bajo esta forma directamente a Murcia), el mayordomo del Seminario se encargaba por entero de su administración: esencialmente, recibir las cuentas y los productos de los administradores locales si éstos no resultaban alcanzados, y pagar los gastos causados (subsidio, excusado y décima; salarios de los administradores locales; costes de transporte de especies o de dinero; labores de recolección y administración, pesado y mermas; salario a los curas por la parte que les correspondía en el beneficio respectivo; etc.). El producto sobrante (que seguía manteniendo en su composición partidas en dinero y en especie) constituía la renta neta a disposición del Seminario. Y decimos a disposición porque en realidad nunca era administrada por otra persona que el mayordomo, incluyendo especialmente al propio Seminario a través de su rector. En este sentido, el rector nunca contraía gasto alguno y menos aún podía utilizar directamente la renta.De modo que las partidas de gasto se hallan subdivididas en gasto ordinario (gastos mensuales fijos: coste de las raciones diarias básicas de alimentos salvo el pan) y gasto extraordinario. Este último grupo incluía, lógicamente, un conjunto de partidas muy diversas, aunque podemos agruparlas en cuatro apartados: compra o arreglo de útiles y enseres domésticos; adquisición de otros alimentos o de materiales para elaborarlos y conservarlos, productos energéticos (aceite para candiles y carbón), y pago de salarios y jornales fijos a individuos tanto del Seminario como del exterior, o contratados de forma eventual. $\mathrm{Al}$ gasto ordinario, por último, se añadía el consumo diario de pan que, en lugar de comprarse, se obtenía del cereal enviado al administrador desde los beneficios. Los gastos ordinario y de pan iban siendo cubiertos por el administrador de acuerdo con unas planillas mensuales facilitadas y firmadas por el rector, en las que se computaba diariamente el número de los individuos presentes en el Seminario, y el precio de la carne asímismo cotidianamente. El procedimiento, por tanto, era casi automático. La actitud pasiva del rector en los aspectos económicos quedaba aún más de manifiesto en relación con los gastos extraordinarios: aquí siempre debía solicitar al cabildo la autorización para contraer el gasto, y una vez concedida (no hemos hallado casos de denegación), el cabildo ordenaba al mayordomo que librase el dinero al rector, cuando no se le daba ya directamente el bien solicitado. 


\section{-Los estudios.}

Dentro de cada apartado, hemos procedido a utilizar la documentación siempre de idéntico modo. Primeramente, efectuamos la descripción de la norma constitucional para después, y siempre que es posible, contrastar su aplicación -con la información proporcionada por la contabilidad- seis décadas más tarde. En cuanto a los Autos, nos permiten efectuar esta labor tanto en lo relativo a los propios tiempos fundacionales como incluso poder rastrear el proceso de maduración de la norma contenida en las mismas Constituciones. Por lo que atañe al esquema, huelga todo comentario acerca de la inclusión en él de apartados propios del análisis de la vida cotidiana en una institución de este tipo. Más extrañeza y mayor justificación podría requerir el que aparezca un apartado (el primero) destinado al análisis de la dependencia gubernativa exterior del Seminario. Sobre este asunto, es cierto que queda fuera del estricto marco de la vida cotidiana, pero esperamos que se desprenda de cuanto digamos sobre ello la necesidad de incluirlo, aunque sea de forma casi sumaria, por entender que determina enormemente toda la vida del Seminario.

\section{LA DEPENDENCIA CAPITULAR.}

Fundado en 1592 por el -a la sazón- obispo de Cartagena D. Sancho Dávila y Toledo, el Seminario de San Fulgencio puede ilustrar perfectamente la realidad de lo que fueron los Seminarios españoles del Barroco, cuyos rasgos esenciales ya pusiera de manifiesto Martín Hernández en el trabajo citado. En general, "los Seminarios se configuraron como Colegios-internado muy modestos: reducido número de individuos (difícilmente más de 20) dirigidos por un rector, y corta oferta docente, por lo común restringida a la gramática latina, la teología moral y el canto llano. En cambio, todo lo referente a lo que pudiéramos considerar formación moral, cristalizada en el aprendizaje e interiorización durante la permanencia en la institución de unas conductas ejemplares, ocupa el centro y fin de la vida colegial, tal como avanzábamos.

Este carácter, que puede considerarse propio de la Contrarreforma (a fin de cuentas, fue el Concilio de Trento el creador de los Seminarios) y del Barroco, tiene un claro correlato tanto en la estructura jerárquica interna, como en la realidad de la dependencia gubernativa exterior. Dejando para más adelante el primer aspecto, en cuanto al segundo, cabe decir que en principio y por mandato conciliar la máxima autoridad en todo lo tocante al Seminario correspondía al obispo de la diócesis respectiva, que actuaría con la asistencia de algunos comisarios eclesiásticos en ciertos particulares. Sin embargo, la realidad de los Seminarios españoles del Seiscientos fue muy distinta, en la medida en que los capítulos catedrales fueron adquiriendo un ascendiente absolutamente desproporcionado sobre los Seminarios, hasta el punto de que éstos hayan podido ser vistos, sin un ápice de exageración, como meros colegios de acólitos para el servicio del culto en las catedrales.

Todos estos rasgos se observan perfectamente en Murcia. Sin mencionar por ahora pero tampoco sin olvidar- lo relativo al tipo de instrucción impartida y a la onerosa obligación de servicio al coro, el dominio del cabildo sobre el Seminario se desplegaba permanentemente en multitud de aspectos de no poca relevancia: control absoluto de la cátedra de Gramática del Seminario (aspecto de enorme importancia, al que también nos referiremos), pertenencia al cabildo del administrador de las rentas del Colegio e incluso del pro- 
pio rector ${ }^{9}$, concesión de ayudas de costa para diversos menesteres, etc. Las causas de este hecho, en virtud del cual en la práctica el Seminario se hallaba sometido directamente al cabildo en detrimento de la instancia episcopal son básicamente dos. En primer lugar, la genérica representada por la ambigüedad -por así calificarla- de los decretos tridentinos a la hora de delimitar de forma precisa las competencias correspondientes al cabildo y al obispo en la regulación de la vida colegial, hecho éste que dejaba abiertas múltiples puertas para una lectura abusiva por parte de los capitulares. Pero en segundo lugar hay que sumar las circunstancias propias del caso murciano, y ello desde los momentos iniciales. Tal como nos relatan los Autos de fundación, ya entonces el cabildo desempeñó un papel protagonista junto con el obispo Dávila. De ellos se desprende que el cabildo estaba, por principio, muy interesado en la creación del Seminario ${ }^{10}$. Como muestra de esto, hemos de subrayar que el cabildo donó el edificio para albergar el Colegio (el llamado taller de los Andosillas), próximo a la catedral ${ }^{11}$ y pagó la construcción de la fachada delantera en piedra (levantada en 1598). Por otra parte, la contribución que el cabildo hizo a las primeras aportaciones económicas con las que el Seminario comenzó su andadura fue, aunque proporcional a sus rentas, superior en términos absolutos a la efectuada por la mesa episcopal'2. Todo ello hizo que el cabildo se arrogase un cierto patronazgo sobre el Seminario que se iría consolidando indudablemente durante el siglo XVII, si no de derecho sí de hecho, conforme a la práctica habitual del cabildo. En esa consolidación de la que pudiéramos denominar sin más cautela prepotencia capitular sobre el Seminario tuvieron un papel decisivo las circunstancias por las que pasó el mundo eclesiástico murciano durante el siglo XVII, y en concreto el desequilibrio experimentado en la balanza de poder entre el cabildo y la instancia episcopal: el constante cambio en los titulares de esta última (17 pre-

9 Por lo que se desprende de los Autos y de la contabilidad posterior, el cargo de mayordomo estuvo monopolizado por una sola familia, la de los Guerrero, todos ellos racioneros de la catedral.

10 Los Autos comienzan con la comunicación personal realizada por el obispo a los capitulares reunidos en cabildo espiritual ( 3 de agosto de 1592) para que: "se pusiesse en execución, y por la obra el Seminario (...) pues sabían, y entendían el bien que de él havía de redundar a esta Ciudad, y todo este Obispado". A tal efecto no sólo se encontraba ya nombrada una comisión integrada por seis capitulares de distinto rango, sino que uno de ellos, el canónigo Dr. Arce, habia escrito: "un discurso sobre el provecho, que ha de redundar de hacerse el dicho Seminario", cuyo texto no nos ha llegado.

11 El 19 de agosto de 1592, el obispo Dávila pasó a tomar posesión de este edificio, acto que se conmemoró mediante la celebración de una misa solemne a la que asistieron las dos comisiones de consejeros del obispo para el Seminario, diversos diputados de los cabildos eclesiástico y civil, y "otros muchos vecinos", según consta de los Autos.

12 Dávila ordenó realizar dos repartimientos sobre las mesas episcopal y capitular, en 1592 y 1596 . A1 cabildo le correpondió abonar en cada uno de ellos $205^{\prime} 5$ ducados, es decir, un $13{ }^{\prime} 6 \%$ del total frente al $9 \%$ de la mesa episcopal. El resto de la cantidad, hasta 1.500 ducados, fue aportado por los "beneficios, préstamos, terzuelos y capellanías" diocesanas. Estos repartimientos tuvieron carácter único, hasta que el Seminario pudo comenzar a disfrutar -no sin ciertas demoras- la posesión de los tres beneficios citados con que el fundador lo dotó. Precisamente por la liquidación de las cuentas que el mayordomo entregó en 1595 conocemos la serie de bienes y utensilios que éste entregó al rector para garantizar la habitabilidad inicial del Colegio en régimen de internado. Figuran en ella todn tipo de muebles, colchones, ropa de cama y de mesa, cerraduras, sartenes, candiles, tinajas y ornamentos iitúrgicos. Sin embargo, es de notar que no existía más referencia a libros o elementos didácticos que la hecha a un misal romano y a una tabla de las Constituciones originales en pergamino. 
lados a lo largo del siglo) ${ }^{13}$, venía a colocarla en una situación de interinidad casi permanente, amén del correspondiente número de períodos de sede vacante más o menos largos que dichos cambios llevaron aparejados. Por tanto, ni aun en el caso (que no se llegó a dar) de que algún prelado hubiese pretendido actuar en profundidad para modificar y mejorar cualitativamente la situación del Seminario, le habría sido posible mantener la necesaria continuidad en dicha labor. A abonar esta tesis vienen, en definitiva, las dificultades y largos contenciosos con el cabildo por los que hubieron de atravesar los obispos murcianos del Setecientos cuando pretendieron recuperar plenamente el control sobre el Seminario y reformarlo ${ }^{14}$.

\section{GOBIERNO INTERNO: EL RECTOR.}

La dependencia respecto del cabildo constituye tan sólo uno de los rasgos que revelan el carácter barroco de los Seminarios. Pero también el esquema de organización interna, y el modelo institucional, vienen a abundar en este carácter, al adoptarse un modelo que si bien arranca de mucho antes ${ }^{15}$, cristaliza definitivamente durante el siglo XVII. Así, frente a los viejos valores democráticos de las antiguas Universidades, en todo el mundo de la formación superior (tal es también, pese a la pobreza de los contenidos académicos, el caso de los Seminarios) se abre paso "una rigidez de nuevo cuño que aglutina al estudiantado en un círculo estrecho donde se han perdido las ideas participativas, y por lo tanto la posibilidad de contestación justificada; una rigidez acorde con la mentalidad barroca de la Monarquía Absoluta que intenta colocar a cada cosa en su sitio después del desbarajuste social y económico que ha dejado tras de sí el Renacimiento"16. El Seminario murciano, configurado desde el principio como Colegio-internado, siguió de cerca el modelo que se impuso, así pues, durante dicho siglo.

$\mathrm{Si}$ el eje sobre el que se articula la estructura interna del Colegio es la ya avanzada rigidez jerárquica, la figura central dentro de la misma -y primera de las que se ocupan las Constituciones- es la del rector. Acerca de las condiciones previas que se le exigían, únicamente se indica que debía ser sacerdote (Constituciones I,5), lo que basta, empero, para suponerle de edad superior a los colegiales, y sobre todo le coloca netamente al margen y por encima de la comunidad, confirmando el alejamiento de aquellas tradiciones colegiales democráticas. Rasgo que se confirma por el procedimiento de su elección, simplemente confiada al entero arbitrio del prelado $(\mathrm{I}, 1)$. Este era su superior jerárquico en todos los aspectos, al que debía acudir con suma fidelidad en cuanto fuere de importancia $(\mathrm{I}, 3)$.

Antes de entrar en el detalle de sus obligaciones, atribuciones y competencias, en las Constituciones lo que primero se define es el modelo de rector que se busca. Dentro de la

13 Pedro DIAZ CASSOU, Serie de los obispos de Cartagena, Madrid, I895. En cambio, el número se redujo a 7 durante el siglo XVIII, prueba de la importancia creciente que la diócesis de Cartagena fue tomando en el conjunto de las españolas: de diócesis de paso se convirtió en destino final de sus titulares.

14 C. MAS, "De la Ilustración al Liberalismo...", op. cit., pp. 102-108.

15 Vid. MARTIN HERNANDEZ, Los Seminarios españoles..., pp. 182-186.

16 Mario MARTINEZ GOMIS, La Universidad de Orihuela (1610-1807), Alicante, 1987, tomo I, p. 269. 
transmisión de las mencionadas pautas barrocas (aprendizaje del acatamiento a la subordinación jerárquica rígida y de una disciplina interiorizada más por un constante refuerzo imitativo que por una mera racionalización), al rector le corresponde el papel esencial ante los colegiales: él ha de ser el espejo del modo de vida que éstos han de asumir, y su constante paradigma de comportamiento; es decir, de las normas plasmadas en las conductas exteriores predeterminadas que se esperan y exigen socialmente al sacerdote católico.

El oficio que le correspondía era, de modo general, el de: "governar el Collegio con toda paz, y quietud, conforme a las constituciones que ay en él, y procurar con zelo Christiano y diligencia, que los Collegiales vivan virtuosa y exemplarmente, y acudan con summa puntualidad al servicio de la Iglesia, y se aprovechen en el estudio de las letras, que son los tres fines principales que el sancto Concilio de Trento se propuso" en la creación de estos Seminarios (I,1). Para ello, se reputa como medio más eficaz, que se declara inmediatamente, el de mostrar la: "integridad de sus costumbres y buen exemplo de vida". Sólo en la práctica de este comportamiento, afirman las Constituciones, podrá fundamentar el rector su autoridad, que por tanto es ante todo una autoridad moral: "De donde resultará que los que están debaxo de su govierno, aprenderán a cumplir con sus obligaciones, y él los podrá reprehender quando faltaren con efficacia y libertad" (I,2). Por dicha razón, se hace especial hincapié en que su trato con los colegiales sea con todos "grave y apacible", como forma de no establecer unos distingos que sólo conducen a provocar quejas y emulaciones $(I, 4)$. En contrapartida, las Constituciones exigen que todos los colegiales respeten y traten al rector con mucha humildad y reverencia, dentro y fuera de la casa, de palabra y de obra. Si esta norma no se respetase se impondría el castigo correspondiente, siempre según la gravedad de la falta, por el rector o, en casos más graves, por el prelado. Ahora bien, "esto no estorva que el que en alguna cosa se sintiese agraviado del rector, no pueda recurrir, o al Prelado, o alguno de los Comissarios señalados" (V,2).

En cuanto a las funciones concretas que se explicitan en las Constituciones para el rector, escuetamente enumeradas son las siguientes: decir misa diariamente en la capilla del Colegio (I,5); celar por el cumplimiento puntual de las Constituciones, haciéndolas leer frecuentemente $(I, 6)$; visitar a menudo o al menos una vez al mes los aposentos de los colegiales; hacer respetar "diligentissimamente" la clausura del Colegio (I,8); estar presente siempre en el refectorio, dando la bendición y las gracias en la mesa $(I, 9)$; acompañar siempre a los colegiales cuando salieran en comunidad (a la Iglesia mayor, procesiones generales, etc), colocándose en último lugar para mejor asegurarse de que guardaban el debido orden y compostura, así como el buen cumplimiento de las ceremonias en la catedral $(\mathrm{I}, 9)$; recibir y guardar hasta la salida definitiva del Colegio los objetos de viaje que trajesen los nuevos colegiales que ingresaban $(I, 10)$. En el orden económico, celaría con "particularissimo cuydado" los papeles económicos del Colegio (citándose expresamente bulas, escrituras de rentas y libros de cuentas), para lo que existiría un archivo, una de cuyas dos llaves la tendría él mismo y la otra la persona que nombrase el prelado.

Estas funciones rectorales sobre el gobierno, se explicitan más aún cuando las Constituciones hablan de los colegiales. Así, habría de cuidar el arreglo de las coronas de la cabeza de los colegiales, regularmente cada quince día (III,2); ordenar que se les diesen las sobrepellices para el servicio de la Iglesia (III,3); velar por que los colegiales guardasen 
la debida compostura en el arreglo del traje exterior, sin vestir las cosas prohibidas, so pena de que el rector se las quitase y les impusiese la penitencia correspondiente (III,4). Al rector correspondía también el nombramiento de los oficios del Colegio en las personas de los colegiales que más a propósito considerase (IV). Asímismo, se aseguraría de que todos los colegiales confesasen y comulgasen en el lugar que él diputase durante los días del año que se señalaban $(\mathrm{V}, 1)$, asignaría los aposentos nombrando el compañero y estableciendo el tiempo que hubiesen de permanecer en el mismo, y daría licencia para visitar aposento ajeno $(\mathrm{V}, 5)$. Era necesaria igualmente la licencia del rector, con necesidad justificada, para acostarse o levantarse fuera de la hora señalada $(V, 7)$. El era el primero también en descoger la servilleta en el refectorio ( $V, 8$ ), y debía dar las licencias para salir del colegio o entrar en casa alguna de la ciudad, para lo que se le daría compañero al colegial $(\mathrm{V}, 10)$. Señalaría un familiar por enfermero de cada enfermo y si preciso fuere, un sobrestante del enfermero $(\mathrm{V}, 12)$. $Y$ en caso de muerte, por último, asistiría con la comunidad al entierro $(\mathrm{V}, 13)$

La autoridad y funciones del rector en el interior del colegio eran, por lo tanto, prácticamente absolutas: respondían a una rigidez jerárquica en la que el superior sólo está ligado a sus inferiores por un vínculo esencialmente moral y paradigmático. Esto incluye, como refuerzo normativo, la posibilidad de imponer por sí mismo las penas necesarias para la corrección de las conductas de los colegiales. Sin embargo, esta autoridad no era enteramente arbitraria, en la medida en que el propio rector estaba a su vez sometido al prelado y en que -por otra parte- los castigos (aunque no las transgresiones) quedaban claramente sujetos a límites: carcelería en los aposentos del colegial infractor, privación de toda o parte de la porción alimenticia (salvo el pan): "o con otras penas, y por el tiempo que la prudencia le dictare". Recordemos que en los casos más graves, el rector habría de comunicar la falta y confiar el castigo al obispo, quien por su parte llegaría si fuera preciso hasta la expulsión definitiva del colegial $(\mathbf{I}, 6)$. A diferencia de los colegiales, el rector no tendría hábito especial, sino sólo el de simple sacerdote. Queda, pues, perfectamente claro cuanto postulábamos en el sentido de ser la del rector la única autoridad interna existente en el Colegio, así como la existencia de una neta barrera que diferenciaba a éste del conjunto de los colegiales. Y ello con independencia de si éstos desempeñaban alguno de los oficios que era necesario cubrir para el funcionamiento diario de la institución, de los que luego hablaremos.

En los Autos, la figura del rector aparece mencionada por vez primera en 1594, dos años después de la fundación. Entre esa fecha y fines de siglo, el cargo fue ocupado al menos por cuatro personas distintas, todos presbíteros beneficiados o curas de la catedral ${ }^{17}$. La ración diaria que le correspondía, según las Constituciones era doble a la de los colegiales: 4 libras de pan, dos de carnero, media acumbre de vino y: "las demás menudencias de antes y postres que se darán a cada uno de todos los Collegiales". Ello se justificaba porque se le permitía tener un criado en el colegio.(III,1). Además, le tocaba un salario anual

17 En el periodo correspondiente a la contabilidad, los rectores fueron el conocido sacerdote y poeta Jacinto Polo de Medina (hasta abril de 1667); Diego Carreño (fiscal del Obispado) desde esa fecha hasta julio de 1672; y el licenciado Juan Vicente Ochoa, desde agosto del mismo año. 
de 50 ducados $(\mathrm{I}, 12)$. Sin embargo, consta por los Autos que se le comenzó dando 1 libra de carnero (valorada en 26 maravedís) más otros 14 maravedís para vino y 3 libras de pan. Poco después se pasó a libra y media de carnero, 4 de pan y medio real para vino. De los Autos se desprende, sin embargo, que desde estos primeros tiempos se le entregaban los 50 ducados de salario. Si saltamos a los documentos de la década de 1660 , el rector recibía ya sus 2 libras de carnero y 4 de pan diarias, más 40 maravedís (es decir, 10 cuartos) para vino y recados de olla, manteniéndose el salario anual en 50 ducados. Por supuesto, se refleja también toda la asistencia que se le prestaba en vestuario y calzado, e incluso alguna pequeña partida en dinero ${ }^{18}$. Recordemos también, dado el carácter eminentemente contable de estos documentos, que el rector no tenía capacidad para contraer gasto alguno y menos aún para utilizar directamente la renta, hallándose toda ella administrada y gestionada por el mayordomo.

Aunque no se le nombre en las Constituciones, y por tratarse de un colegial (posiblemente el de mayor confianza entre los más antiguos) deberíamos referirnos a él en el siguiente apartado, hemos de incluir aquí la figura del vicerrector, que el Seminario murciano pronto incorporó siguiendo la tendencia general entre las otras instituciones contemporáneas de su género. En concreto, los Autos lo mencionan por primera vez hacia 1599 , sin mayores precisiones. En los años 60 del siglo XVII, las referencias contables no son mucho más esclarecedoras, aunque sí suficientes como para apreciar el estatuto intermedio, entre el rector y el resto de los colegiales -desde el punto de vista jerárquico- en el que se hallaba situado: recibía 1 libra de carnero y 2 libras de pan, pero sin salario alguno.

\section{LOS COLEGIALES.}

\subsection{Admisión y procedencia.}

La admisión de los colegiales, y la determinación del número que de ellos debía haber en el centro, eran competencias exclusivas del prelado. Sin embargo, se establecía como lo más deseable un total cercano a los 20 , con un máximo de 24 . Todos habían de ser naturales del obispado, conforme mandaba el Concilio, aunque se fijaba un orden de prelación por localidades, bien por su importancia, bien por poseer el Seminario rentas en ellas: 6 colegiales de Murcia, 2 de Cartagena, 2 de Lorca, 3 de Chinchilla, 2 de Villena, 1 de Hellín, 1 de Jorquera, 1 de Albacete, 2 de Las Peñas de San Pedro, y 2 de Almansa. El resto de las plazas, hasta cumplir las 24 , quedarían cubiertas a razón de una por cada uno de los demás lugares del Obispado, comenzando por los más importantes. Hemos de entender que el máximo establecido se ajustaba a la cuantía de las rentas con que en ese momento se contaba -o se pensaba contar de inmediato-, pero acto seguido se declaraba que "estando acabada la obra del Collegio", podría aumentarse el número de colegiales confor-

18 En realidad, la única partida de este tipo figura en el ejercicio de 1666 , cuando el rector del Polo de Medina recibió 25 reales más al dejar el cargo. 
me a la renta y parecer del prelado y $\operatorname{comisarios}^{19}$. En cualquier caso, el coste de mantenimiento de cada colegial se estipulaba en 50 ducados. Tal era la cantidad que se les mandaba asignar. Pero aunque ello no se declare expresamente en las Constituciones, dicha cantidad se hallaba aplicada a la dotación de idéntico número de becas, de las que al colegial sólo correspondía el usufructo. En ese sentido se entiende el párrafo en virtud del cual: "en quanto fuere posible a todos quepa parte del fructo y utilidad del Colegio" (II,1). Por lo demás, semejante sistema va claramente destinado a establecer como prioritario un alumnado de tipo interno (becas de gracia), frente a los porcionistas y semiporcionistas. Sabemos, sin embargo, que estos últimos llegaron a existir, junto a los externos, pero sólo durante el siglo XVIII.

Desde el punto de vista efectivo, los Autos nos informan que el 21 de agosto de 1592 ya se hallaban elegidos los primeros colegiales. Comenzaron siendo 12 , a quienes se seleccionó por su origen procurando respetar el criterio que reflejaron las Constituciones en este punto: 4 de Murcia, 2 de Cartagena, 2 de Lorca, 1 de Villena, 1 de Chinchilla, 1 de Jorquera y 1 de Hellín ${ }^{20}$. Sin embargo, sólo las cuentas de los años 60 nos permiten hacer-

19 Ya hemos dicho que el proceso de plena incorporación del Seminario al disfrute de las rentas de los beneficios que le fueron anexados fue dificultoso y experimentó alguna moratoria. En 1594 (Autos), y antes de verse forzado a ordenar la realización del segundo reparto provisional, Dávila eligió e incorporó los futuros beneficios permanentes. Tales fueron el simple servidero de la parroquial de Santa María de AImansa, el préstamo de la parroquial de Santa María y San Salvador de Chinchilla, y el préstamo de la villa de Las Peñas de San Pedro, todos ellos lugares enclavados en el arco norte de la diócesis, en tierras de secano y monte y por tanto de economía relativamente estable frente a las fluctuaciones coyunturales. En el momento de la elección, todas estas rentas se encontraban poseídas por particulares (dos presbíteros y un canónigo). En principio -procurando respetar siempre el texto conciliar-, se declaró que quedaban incorporadas sin perjuicio de las obligaciones y cargas que tuviesen ni del derecho de sus poseedores a llevarlas y a poseer sus rentas mientras viviesen (por eso tuvo que efectuarse el segundo reparto). El primer beneficio en vacar fue el de Las Peñas de San Pedro, seguido del préstamo de Chinchilla, cuyos titulares murieron -respectivamenteen febrero y agosto de 1597.

El Seminario tomó posesión de ellos de inmediato. El beneficio simple de Almansa vacó en 1598. Pero por otra fuente distinta de los Autos sabemos que en el mismo año dos familiares de los antiguos beneficiados pretendieron seguir obteniendo las rentas de los de Las Peñas y Almansa, y llegaron a lograr una bula de Clemente VII reconociéndoles este derecho en octubre de 1598. Dávila se vió forzado a solicitar por su parte una orden de Felipe III (Real Cédula de 1599) suspendiendo la ejecución de dicha bula (Archivo Diocesano Murcia, Protocolo y libro becerro del Seminario, manuscrito, doc. $n^{2} 6$ ). Se desencadenó entonces un pleito en la Curia romana -la que, por razones que ignoramos, prestó oídos a los familiares de los antiguos beneficiados- alargado hasta la resolución papal de enero de 1614 (Bula de Pio V, Protocolo y libro becerro..., doc. $\mathrm{n}^{\mathrm{0}}$ 13), en forma de convenio entre las partes. El pleito aún colearía en Roma hasta 1639, pues el propio defensor del Seminario interpuso embargo contra los bienes y rentas de éste para que se le abonasen las cantidades que de su bolsillo tuvo que suplir en el pleito. El asunto se solucionó en 1639 , cuando el Colegio terminó por pagar a su antiguo defensor un total de 25.000 reales (Frotocolo..., doc. $n^{\text {? }}$ 14). De tan poco edificante historia podemos obtener alguna conclusión: el desinterés de Roma respecto de los Seminarios, postergados ante la proverbial avidez monetaria de una Curia romana que una vez más supo sacar dinero de un pleito sin importarle mucho el contexto ni las consecuencias de tales dilaciones; la nula presencia del obispo y escasa del rey; y por último, el desinteresado interés del Cabildo, que aprovechó la ocasión para intervenir como único valedor del Colegio, reforzando así su control sobre la institución.

20 En ningún caso durante estos primeros años llegó a haber más de 14 colegiales. 
nos una buena idea sobre este particular. Durante ese tiempo, el número máximo de colegiales ( in contar rector, cocinera o familiares) fue de 21 -en 1664- y el mínimo de 13 -en 1666-: lo habitual era que se mantuviese entre 14 (en los períodos estivales) y 18.

En relación con este número de alumnos, nos hemos permitido calcular, sobre la base que nos ofrece la contabilidad, cuál era el máximo posible que de ellos podía alojar el Colegio. Desde esta aproximación estrictamente económica, el resultado -amén del notorio ajuste a las Constituciones que esto representa- es claro: las rentas existentes durante la década de referencia apenas podían cubrir -en el mejor de los casos- los gastos generados por el mantenimiento de unos 26-27 colegiales $^{21}$, quedando su nivel óptimo muy poco por encima de los 20 . Esto quiere decir, por una parte y exclusivamente desde esta aproximación económica, que el Colegio podía mantener holgadamente a los individuos con que entonces contaba ${ }^{22}$; y por otra, que cualquier ampliación en cuanto a su número había de pasar, bien por un cambio espectacular al alza en la coyuntura (de improbable contemplación en la mente de sus gobernantes), bien por un aumento en el número de los beneficios anexados al Colegio. De hecho ésta sería la solución adoptada nada más comenzar el siglo XVIII por el obispo Belluga cuando se propuso incrementar el número de los colegiales ${ }^{23}$.

Las condiciones que habrían de reunir los colegiales resultan en las Constituciones de la suma de las establecidas por el Concilio, más algún añadido muy hispánico y muy poco evangélico. Entre las primeras se cuentan las de ser pobres ellos y sus padres: "sin patrimonio ni renta ecclesiástica de que se puedan sustentar"; tener entre 16 y 20 años de edad; y que supieran ya leer y escribir, mejor aún si ya tenían principios de Gramática; y sobre todo: "virtuosos, de buen índole, y natural disciplinable, y de quienes se pueda presumir que tienen inclinación y aptitud para el estado Ecclesiástico". Entre las segundas se hallaba especialmente la limpieza de sangre: "sobre lo qual se ha de hazer la información". En último término, esta información comprendería también la que determinaba el propio Concilio sobre ser sujetos hábiles, sin enfermedad o minusvalía (tullido, sordo, ciego; enfermedad contagiosa o que alborotase el Colegio, como gota coral -epilepsia- o falta de juicio), de manera que incluso el que contrajere estos males durante su estancia en el Colegio habría

21 El cálculo se ha efectuado tomando como referencia los datos del año 1669 , que podemos considerar un ejercicio normal, sin ninguna incidencia catastrófica. De acuerdo con esto, era necesario destinar un total de 1.130 '5 reales por individuo y año (si reducimos a dinero el coste del pan) u 819 reales más 730 libras de pan (sin contar con el precio del aceite, que no conocemos). Este era un costo de carácter fijo: esto es, el ingreso de cada nuevo colegial suponía indefectiblemente los 1.130 '5 reales sin posibilidad de reducción, al contrario que los gastos extraordinarios, que sí se veían proporcionalmente abaratados con cada nuevo ingreso. Como quiera que el producto neto anual fue de 37.777 reales, el máximo admisible de colegiales era de $20^{\prime} 64$ con los recursos monetarios reales disponibles (23.342 reales), y de $32^{\prime} 47$ de acuerdo con los recursos de trigo (329 fanegas de trigo, es decir 26.978 libras) acumulados durante ese año.

22 Sólo hubo una ocasión en que hubo que despedir provisionalmente a algunos colegiales por problemas económicos: "(Domingo, 7 de febrero de 1672) este día se retiraron a sus casas quatro colegiales por estar alcançado el colexio". Fueron reincorporándose sucesivamente hasta que el 26 de marzo del mismo año lo hizo el último.

23 C. MAS, “De la Ilustración al Liberalismo...”, pp. 104-105. 
de ser expulsado del mismo (II,2) ${ }^{24}$. Las informaciones comenzaron a verificarse desde el primer momento. Así, según los Autos, para admitir a los primeros ya se hizo averiguación de: "sus limpiezas, legitimidad y buenas costumbres". En cambio, en cuanto a su extracción social sólo se menciona (en 1598) que efectivamente procedían de familias pobres, pero nada sabemos sobre sus edades, y muy poco de las carreras que siguieron al abandonar el Seminario. En este último sentido, los únicos datos -que sólo figuran en la contabilidad- indican que algunos colegiales eran licenciados universitarios poco antes $o$ al abandonar el Seminario, y que otros salieron de él para entrar en religión (sin precisar la Orden). Por último, en cuanto a los años de permanencia en el Colegio, no tenemos ningún dato referido al siglo XVII, aunque durante el Setecientos el tiempo de derecho al disfrute de la becas se situaba normalmente en torno a los siete años.

24 Aunque de tiempos mucho más tardíos -pontificado del obispo D. Manuel Mirallas (1785-1788)-, poseemos un ejemplar impreso del modelo de información para ingreso en el Seminario. A continuación lo reproducimos entendiendo que en lo sustancial era la que se practicaba desde los primeros tiempos:

"Comisión para Pruebas de Colegial de S. Fulgencio.

DON MANUEL FELIPE MIRALLAS, por la Gracia de Dios, y de la Santa Sede Apostólica, Obispo de Cartagena, del Consejo de S.M., \&c.

Por el tenor de la presente damos comisión en forma de derecho a [blanco] para que sobre, y en razón de la Beca de Colegial [blanco] natural de [blanco] reciba información, examinando de su oficio, mediante juramento, y por ante Notario, que dé fe, tres o quatro testigos, personas honradas, y fidedignas, al tenor del Interrogatorio siguiente:

I Primeramente, serán preguntados, si conocen a [blanco]Pretendiente a una de las Becas del Colegio Seminario del Señor San Fulgencio de esta Ciudad, de dónde es natural, y qué edad tiene; digan, y evacuen las generales de la Ley, \&c.

2 Item, si conocen o conocieron a sus Padres, y cómo se llaman, o llamaron; y si saben es hijo legítimo, y de legítimo matrimonio, habido, y procreado durante él, y por tal tenido, y reputado; digan, \&c.

3 Item, si conocen a sus Abuelos Paternos, y Maternos, digan quienes son, $\mathrm{o}$ de donde fueron.

$4 \mathrm{Item}$, si saben que todos ellos, y cada uno de por sí, son, y han sido Christianos viejos, sin ninguna raza, ni mácula de Judios, Moriscos, ni nuevamente convertidos a la Fe, ni penitenciados por la Santa Inquisición, ellos, ni los demás sus ascendientes, y están habidos, tenidos, y reputados por tales Christianos viejos, limpios, sin ninguna mácula de mala generación; y si saben que sus Padres hayan tenido algún oficio vil, que haga al Pretendiente indigno de ser admitido al Estado Eclesiástico.

5 Item, si saben que el dicho Pretendiente es de buenas costumbres, e inclinado a la Iglesia, recogido, modesto, y de buena capacidad para el exercicio de las Letras, e inclinado a los Estudios, y que frequenta los Santos Sacramentos, y es asistente a la Iglesia; digan en esto lo que supieren.

6 Item, si saben que dicho Pretendiente, y sus Padres son pobres, sin bienes raíces, ni caudal, y tanto, que si no entrara su hijo en el Colegio, no le pudieran dar estudio, digan lo que en esto supieren.

7 Item, si saben que el dicho Pretendiente no tiene enfermedad alguna contagiosa, de humores gálicos, lamparones, mal de San Lázaro, tiña, ni otras semejantes, digan lo que supieren.

$Y$ hecha dicha información, hará el expresado Comisionado se ponga a su continuación el mote, y Partida de Bautismo del Pretendiente. Y todo ello, con su parecer, y dictamen jurado de la fe que se les deba dar a los testigos; de la vida, y costumbres de dicho Pretendiente, y su limpieza de sangre, originales las remitirá ante Nos, y a manos del infrascripto nuestro Secretario de Cámara, para que en su vista providenciemos lo conveniente. Dada en [blanco]

Por mandado de S.I. el Obispo mi Señor:

Gratis omnino." (Archivo Catedral Murcia, legajo 264). 


\subsection{Vestido y alimentación.}

Desde su entrada en el Colegio, los colegiales habrían de vestir el hábito propio de su condición y distintivo del Colegio. En San Fulgencio, éste sería un manto redondo de paño pardo: "no más largo que quanto bese la tierra", y una beca de veintidoseno verde: "de anchura de una quarta doblada, y que cruzada delante sobre el pecho, sea detrás por ambos lados tan larga como el manto, y todos traerán bonetes de una forma, y coletas con sus coronas abiertas de razonable tamaño" (III,2). Estas ropas, que se les entregarían al ingreso, serían renovadas cada dos años, y con las viejas se les harían ropas que sirviesen en el interior de la casa. Además, dos veces al año (por Navidad y San Juan), se le daría a cada uno un par de zapatos, y un bonete, así como las sobrepellices que pareciere al rector para servicio de la Iglesia (III,3). Por otra parte, ya nos hemos referido a la prohibición de llevar bajo los mantos cualquier indumentaria lujosa o extravagante, desacorde con la compostura propia del seminarista, prohibición que por supuesto se extendía a la de portar armas $(\mathrm{III}, 4)$.

Los colegiales tenían asegurado junto al vestido, el alimento correspondiente. A cada uno se le proporcionaría diariamente una ración consistente en 2 libras de pan y 1 de carnero. En "Ios días de pescado" se les daría el correspondiente al que se pudiese comprar con el precio ordinario de la carne ${ }^{25}$. Esta ración básica se completaba con verduras, especias y tocino, aunque en este caso sin fijar cuota individual, sino la suficiente para todos. Por último, en concepto de antes y postre se gastarían cada día 8 maravedís por colegial, bien entendido que: "en lo que el Rector determinare". En determinadas fechas (primero de las tres Pascuas, Corpus, Asunción, Navidad, San Fulgencio, domingo de quincuagésima y martes de carnaval) el valor de las porciones sería doblado, gastándose también en los alimentos que el rector determinare. Quedaba absolutamente prohibido que nadie trajese de fuera, ni al refectorio ni al Colegio, otra comida que la dicha, así como pedirla (III,5).

En efecto, a los colegiales estudiantes se les comenzó asistiendo en su vestuario, consistente en: "lobas redondas, medios mantos, y Becas verdes, sin roscas, que traygan por el cuello". Recibieron durante los primeros tiempos media libra de carnero como ración (hemos de suponer que también el pan), que en 1596 se cambió por medio real para carnero y dos libras de pan diarias, más real y medio de complemento para: "ante, y pos, y carbón", esto último repartido entre todos. En 1599 esta ración fue aumentada significativamente a 1 libra de carnero y 2 de pan por colegial (la básica fijada por las Constituciones), más un complemento de dos reales diarios para todos destinado al gasto de sal, agua, especias y otras cosas. Desde 1600 se les comenzó a entregar ya a cada uno y por cuenta del Colegio dos bonetes y dos pares de zapatos al año (San Juan y Navidad), así como mantos, becas y sobrepellices cuando los necesitasen. También partir de entonces, cada uno debió llevar consigo la propia cama al ingreso.

La situación de relativa comodidad que nos revelan los datos de la década de 1660 se confirma nada más repasar la cuantía de las raciones. Bien es cierto que no se han produci-

25 Queremos subrayar aquí -ante los investigadores interesados en estas cuestiones- que la contabilidad del Seminario nos permitiría conocer día a día el precio de la carne en la ciudad de Murcia durante los años señalados, y en general, de otros muchos artículos, tanto de consumo como salarios, bienes, etc. 
do aumentos, e incluso en la carne hay un pequeño descenso, pero desde el punto de vista calórico el aporte sigue siendo más que suficiente y -lo que es más importante- no se aprecia en todos estos años ni la más mínima irregularidad cotidiana: los colegiales reciben tres cuartos de libra (12 onzas) de carnero más 2 libras de pan cada uno y un complemento en dinero diario prorrateado en 2 cuartos ( 8 maravedís) para antes. Se mantiene también un reparto cotidiano de 58 maravedís para recados de olla diarios de la comunidad ${ }^{26}$. Los colegiales, por tanto, seguían sin percibir -y así continuarían siempre- ningún tipo de dinero en mano. Lo que no impidió, por ejemplo, que en 1664 el deán ordenase que se diese un ducado adicional por mes a los 6 colegiales modernos que asistían al servicio ordinario de la catedral, para que en los días mayores pagasen al preceptor y maestro de gramática que en hora extraordinaria y "fuera de su obligación" tenían ajustado para que les leyese por no poder asistir -a causa de dicha obligación- durante las horas a las que habitualmente se impartían esas clases en el Seminario.

Los gastos por compra de complementos y renovación de vestuario también aparecen repetidamente en esta contabilidad. A modo de ejemplo, en octubre de 1665, una orden del Provisor diocesano autorizaba que se comprase un manto al colegial Jacinto Oliver, y que se hiciesen sobrepellices por cuenta del Seminario "atento los dichos colegiales tienen necesidad de ellos (sic) y por ser pobres y no tener con qué haçerlas y se sirba el culto divino con la deçencia y adorno que se requiere". No sólo sobrepellices: se consignan bonetes y, sobre todo, zapatos aunque no con la periodicidad establecida en las Constituciones, sino a medida que van haciendo falta.

Alguna otra situación en este sentido sólo se da en una ocasión, aunque podemos pensar que se repetiría en circunstancias semejantes. Es el caso de un antiguo colegial (el licenciado Peral) a quien se concedieron 100 reales como ayuda de costa para vestuario, atendiendo a que -pese a no pertenecer ya al Colegio- había servido muchos años en él y había renunciado a su plaza en favor de otro sin que hubiese expirado el tiempo que legítimamente le pertenecía disfrutarla.

\subsection{Una rutina buscada.}

El núcleo de la normalización de lo que podemos considerar discurrir cotidiano de la vida de los seminaristas se halla reflejado en el capítulo $\mathrm{V}$ de las Constituciones. De su lectura termina de configurarse el tercer rasgo que perfila el carácter barroco que hemos aplicado al Seminario: junto a la dependencia exterior y la rigidez jerárquica interna, nos referimos ahora al aprendizaje de las conductas de acuerdo con los moldes que hemos venido glosando. Al hacer inventario de estas cuestiones, será necesario -por otra parte- volver a repetir, ahora desde el prisma de los colegiales, mucho de la ya dicho a propósito del rector, en prueba de representar éstas la principal preocupación que alentaba en las Constituciones.

26 El aporte calórico resultaba incluso excesivo: la ración básica de un colegial aportaba -de acuerdo con el peso de ésta- un torno a las 2.500 calorías en pan más unas 1.000 en carne. Evidentemente, la falta de otros alimentos habría causado importantes desequilibrios en determinados principios inmediatos (proteínas y vitaminas). Pero las partidas de gasto extraordinario confirman que la ración básica se veía completada en grado suficiente con otros alimentos (verduras, huevos, queso, legumbres, miel, azúcar...). 
Dado que el fin primordial de la formación de los seminaristas era el de: "poderse conservar en temor de Dios nuestro señor, y aprovechar en virtud", en primer lugar todos deberían confesarse y recibir juntos la comunión durante los días señalados ${ }^{27}(\mathrm{~V}, 1)$. En segundo lugar, tenían la obligación de respetar al rector de palabra y de obra aunque -como se ha dicho ya- con la posibilidad de recurrir ante el prelado en caso de sentirse agraviados $(\mathrm{V}, 2)$, pero también la de guardar respeto mutuo y buen trato con los compañeros $(\mathrm{V}, 3)$. $\mathrm{Y}$ en tercer lugar, deberían leer periódicamente -y oir leer cada principio de mes- las mismas Constituciones. De hecho, el que entrare nuevo debería leerlas y considerarlas muy despacio: "antes que sea recibido por la communidad" $(\mathrm{V}, 4)$.

Cada uno tendría su propia cama, y se alojaría en el aposento que se le señalare con uno o varios compañeros, sin posibilidad de replicar sobre esta cuestión. Ya sabemos que deberían tener siempre patentes sus aposentos al rector para que éste los visitase en toda hora, incluyendo las cajas y baules; que se les prohibía a todos entrar en cualquier otro aposento sin licencia del rector $(\mathrm{V}, 5)$; y que tampoco podían acostarse o levantarse fuera de las horas señaladas sin licencia expresa $(\mathrm{V}, 7)$.

Quedaban igualmente prohibidos todos los juegos de naipes, o en general vedados, autorizándose sólo y durante las horas que se señalaren los que se indicase, con tal que no se jugase dinero ni cosa de valor, ni provocasen pendencias o voces descompuestas. En cambio, el que supiera tocar algún instrumento, podría hacerlo mientras los demás jugaban, con tal que los sones fuesen honestos $(\mathrm{V}, 6)$.

En el refectorio, todos entrarían juntos cuando se les diese la señal; responderían a la bendición de la mesa y a las gracias, y se sentarían conforme a las órdenes que tuvieren o a la antigüedad en el Colegio. Ninguno descogería la servilleta sin haberlo hecho antes el rector, se les exigía ser muy limpios y compuestos en la mesa, y deberían estar muy atentos a lo que se leyere. Si faltase algo en la mesa, harían señal con el cuchillo, para llamar al que sirviese la mesa, comunicándoselo: "con pocas palabras y voz baxa, y fuera de esto, todos guarden silencio mientras durare la comida" $(\mathrm{V}, 8)$.

Además de la obligación de guardar en sus personas y aposentos la limpieza y el aseo, todos deberían acudir juntos cuando se tocase a barrer. Tenían prohibido entrar en las oficinas de la casa (cocina o despensa) sin licencia salvo los que tuvieren oficio particular que les obligase $(\mathrm{V}, 9)$.

Las salidas del Colegio también estaban seriamente reguladas. Por supuesto, ninguno podría salir del Colegio ni entrar en ninguna casa de la ciudad sin licencia del rector, quien le señalaría compañero. Si la salida fuese para viaje, se hacía necesaria la licencia del obispo, quien lo autorizaría sólo entre las fechas que se solicitasen. El viaje habría de hacerse: "vía recta, sin que a la yda ni a la buelta se detenga en parte de la ciudad". A este efecto, se llevaría un libro registro de ausencias, a fin no sólo de controlarlas, sino de descargar el gasto correspondiente a ese colegial durante el tiempo de ausencia (V,10-11).

La asistencia en la enfermedad y el ceremonial de la muerte quedaban estrictamente regulados. A cualquier enfermo se le asistiría con "Médico, barbero y medicinas", señalán-

27 Primer día de Adviento, tres primeros días de las tres Pascuas del año, Ascensión, Concepción, Purificación, Navidad, Anunciación y Asunción, San Pedro y San Pablo, Santiago, San Fulgencio, Miércoles de Ceniza, Jueves Santo y Todos los Santos. 
dosele por el rector un familiar como enfermero. Si la enfermedad fuese creciendo, se nombraría otro colegial más como ayudante del enfermero, encareciéndose por otra parte al enfermo que fuese muy obediente a los que le curaren: "llevando con paciencia su trabajo, como venido de mano de Dios nuestro Señor" $(\mathrm{V}, 12)$. El enfermo, nada más aparecer la enfermedad, debería confesar, y si el mal fuese adelante, recibiría la comunión con el acompañamiento de todos los colegiales con sus sobrepellices, lo que también se haría al administrársele la Extrema Unción. Si moría en el Colegio, o fuera de él pero en Murcia (habiéndo salido con la debida licencia) el rector con todos los colegiales asistirían con sobrepellices al entierro: "fuera de aquellos que llevaren las andas con el cuerpo, que estos yrán con mantos y con sus becas a un lado en señal de luto". Todos los que el mismo día o el siguiente fueren sacerdotes dirían por el difunto una misa, y los demás el oficio de difuntos $(\mathrm{V}, 13)$.

Pese a la importancia de estos asuntos, es cierto que ni los Autos ni la contabilidad posterior llegan a proprocionar indicaciones directas sobre ellas: extremo lamentable, pero que sin duda nos hace pensar que en realidad -como venimos afirmando- hubo pocas alteraciones realmente notables que consignar en el seguimiento de tan estricta disciplina. En otras palabras, podríamos decir que la vida cotidiana en el Seminario transcurría por cauces que más allá de lo rutinario, casi rayaban en lo buscadamente anodino. Las cuentas manejadas, en materia de diversiones, sólo reflejan los días de ración doble (según prescribían las Constituciones), y como auténtica diversión la fiesta de San Fulgencio y una corrida de toros al año (en lo que se gastaban 20 ducados y 150 reales, respectivamente). En cambio, la Cuaresma no sólo era respetada -por descontado- escrupulosamente desde el punto de vista alimenticio, sino que cada año se compraban bulas para todos los individuos del Seminario (incluidos los fámulos). La inversión, por así decirlo, en material docente es, sin embargo prácticamente nula: durante todos estos años, tan sólo se compró un libro, sin especificar título, "para leer en el refectorio", por importe de 22 '5 reales.

Incluso los sucesos extraordinarios que podían alterar la vida de la comunidad eran, aunque aleatorios, casi previsibles: las avenidas del río son los únicos que podemos consignar según las cuentas, a causa de los perjuicios que se seguían dada la proximidad del Colegio al cauce del Segura. La del 15 de marzo de 1672 (mencionada en las hojas contables con un lacónico: "este día se salió el rio") fue la más grave: a lo largo del año, y después de esa fecha, hubo que pagar 159 reales a tres obreros por limpiar y desaguar el Colegio, quitar la tierra de un pedazo de la muralla que se cayó en la puerta que daba acceso del Colegio al campo, y echar suelo a la carbonera. Aparte, se pagaron 39 reales a un maestro carpintero por arreglar esas puertas, que la crecida había quebrado y quitado de su sitio; y otros 152 por arreglo de los tejados y otras cosas "maltratadas por el rayo", hacer el brocal del pozo de la cocina y echar portales a las puertas. Y en fin, se pagó la parte correspondiente al Seminario de los jornales debitados en concepto de limpieza de la calle de frontera del Colegio a causa del tarquín que en ella dejó la salida del río.

Mención aparte merecen, no ya los hechos extraordinarios que afectaban a toda la comunidad, sino a los individuos separadamente: nos referimos a las enfermedades. La huella que dejan éstas en la contabilidad se refiere únicamente a la alimentación, las medicinas, y los servicios médicos. En efecto, cuando un colegial caía enfermo, el hecho quedaba inmediatamente reflejado en las cuentas diarias porque, amén de anotarse ("hoy cayó enfermo...", y el nombre del colegial), a la ración habitual se le añadía bizcocho hecho en el 
Colegio (en cuyo caso aparecen las compras de huevos, miel y azúcar) o comprado. No es fácil precisar las enfermedades que afectaban a los colegiales, puesto que sólo conocemos los diagnósticos médicos indirectamente a través de las medicinas suministradas; y aunque los conociéramos, seguiría siendo difícil trasladarlos a terminología actual por el tipo de medicina que a la sazón se practicaba, totalmente situada en la tradición galénico-hipocrática, y por tanto basada en la teoría de los humores (flema, bilis, cólera y sangre) y de sus distintas combinaciones: sólo en un caso, por el específico utilizado (granatores) podemos afirmar que se trataba de una parasitosis intestinal. Consecuentemente los remedios empleados son siempre de tipo tradicional, sin recurso a los químicos: en esencia, los que más se repiten son el oximiel (para arrancar los gruesos humores), alchermes (para muchas enfermedades), llantén (para detener las efusiones de sangre), y siropes, jarabes, infusiones y ungüentos de rosas, ajenjo, limón... ${ }^{28}$. En fin, las cantidades gastadas en medicinas resultan muy variables de un año a otro, oscilando entre los 94'5 reales de 1667 y los 395 de 1668 , sin que parezca que mediara en ello ninguna epidemia.

Por este tipo de asistencia, el cirujano y el médico recibían los 14 (el primero) y los 12 (el segundo) ducados anuales que mandaban las Constituciones, en dos medias pagas cada uno. Pero su trabajo no terminaba aquí. Esos salarios sólo incluían los servicios habituales, pues cuando se presentaban situaciones imprevistas, habían de abonarse aparte. Estos casos no son nada infrecuentes. Basten algunos ejemplos. En mayo de 1665 hubo que pagar un extraordinario al cirujano en concepto de haber empleado mes y medio para curar dos granos en los brazos al colegial Francisco Guitarte, al colegial Pedro Caravaca de un golpe en la pierna, y al fámulo refitolero de "una descalabradura". En agosto de 1667 se le pagaron 20 reales al mismo sangrador por curar un brazo al licenciado Granados, y en octubre otros 12 por "visitar" al colegial Ambrosio García. Y durante el siguiente año, nuevamente el cirujano cobraría 50 reales por 30 días de asistencia al licenciado Salcedo para curarle una oftalmia "y una fuente que le ha abierto", y otros 24 reales por asistir y curar a otro colegial de "una apostema en una asentadera". De lo que se deduce que -como era frecuente- era el cirujano, barbero o sangrador flobotomiano quien se encargaba en la práctica de realizar la asistencia y cura: durante todos estos años, no existe ninguna minuta extraordinaria expedida por el médico.

\subsection{Oficios internos y familiares.}

Todos los colegiales quedaban obligados, sin por ello alcanzar en ningún momento la condición de superior jerárquico, a ir ocupando los oficios para los que fuesen nombrados (en todo caso por el rector y por el tiempo que éste señalase) y que resultaban necesarios para el funcionamiento interno del colegio. Tales oficios eran los de: maestro de ceremonias, portero, lector, panadero, y sobrestante del sacristán, cuyas funciones son las obvias y

28 Queremos expresar aquí nuestro agradecimiento al Dr. Josep Bernabéu, del Departamento de Historia de la Medicina de la Universidad de Alicante, por la paciente atención que nos ha dedicado para ayudarnos a desentrañar las dificultades propias de la lectura de las recetas de la época, y su interpretación. En cualquier caso, como obra de referencia, of. Collegium Valentinorum Pharmacopolarum Officina Medicamentorum, Valencia, V. Cabrera, 1698. 
propias de cada cargo. Mención aparte merecen los familiares, en número de tres (despensero, cocinero y sacristán), que serían nombrados por el obispo entre los estudiantes virtuosos del obispado, y cuyas obligaciones genéricas consistían -según las Constitucionesen acudir a la mesa cada día durante la comida y la cena, a barrer y a todo lo que les mandase el rector (IV, 1-13).

La verdad es que ni los Autos ni la contabilidad proporcionan la mas mínima referencia respecto de los oficios desempeñados por los colegiales. Algo más sí sabemos sobre los fámulos. En 1595 (y en los Autos) se menciona a los fámulos despensero y cocinero, aunque parece que interinamente el cargo estaba cubierto por una sola persona, del que se dice percibía medio real de carne y dos libras de pan diarias; y un ama que a su vez cobraba medio real de carnero, 2 libras de pan y 24 maravedís diarios para el gasto de leña. En la contabilidad posterior estos cargos ya se han diferenciado claramente, aunque nunca se menciona al sacristán (posiblemente porque sus funciones fueron asumidas, bien por un colegial, bien por alguno de los otros dos fámulos). Así, el familiar gastador y la cocinera no recibían ración diaria de carne (sí las 2 libras de pan), aunque se les computaba real y medio diario a cada uno -previsiblemente destinado a compra de comida-, amén de un salario mensual de 340 maravedís a la cocinera y de 272 al gastador. En situación semejante se hallaba el refitolero, aunque en un menor nivel económico: 2 libras de pan y 9 cuartos (36 maravedís) diarios, y un salario mensual (sólo a partir de 1671) de 136 maravedís (4 reales). Por último, podríamos incluir aquí los 46 reales mensuales que se le abonaban a una lavandera por sus servicios, sin ningún derecho a ración.

\section{LOS ESTUDIOS.}

A causa de sus especiales características, creemos que la cuestión de los estudios en el Seminario debe abordarse mediante un tratamiento diferenciado respecto de las tratadas anteriormente. En sí misma, la escasa relevancia que adquieren los contenidos docentes en el Seminario, y la forma en que son orientados, ya viene a constituir uno más de los rasgos barrocos en los que venimos insistiendo. Pero se trata, además, de un aspecto que contribuye sobremanera a clarificar alguno de los puntos anteriores, y en concreto, el de la prepotencia capitular.

En punto a las obligaciones de aprendizaje específico, las Constituciones se limitaban a recordar a los colegiales, primeramente, que todos debían aprender el canto y las ceremonias del culto conforme al ceremonial $(\mathrm{V}, 14)$; y de forma aún más general, que fueran muy diligentes y asiduos en sus estudios, guardando las horas y ejercicios que los maestros les señalaren $(\mathrm{V}, 15)$. Ambos mandatos, en la realidad, se concretaron en tres distintos tipos de contenidos docentes.

En primer lugar, sabemos -por una fuente muy posterior- que ya antes de 1600 los colegiales recibían enseñanzas de canto por parte del Maestro de Capilla de la catedral, y lectura del Breviario y Concilio ${ }^{29}$. Ahora bien, ¿acudían también a la catedral para oír las explicaciones del Lectoral y del Penitenciario, para su formación eucarística y moral? ¿La com-

29 Archivo Histórico Nacional, Consejos, legajo 5.496, "Diligencia de visita...(1815)", informe del rector del Seminario de 15 de junio de 1815. 
pletaban, por el contrario, en las aulas de los conventos murcianos una vez salidos, o incluso durante su permanencia en el Seminario? ¿o, simplemente, no recibían enseñanzas organizadas en estas materias?. Se trata de preguntas sobre las que no poseemos ningún tipo de dato. Lo que sí podemos decir, sin sombra de duda, es que al menos la asistencia al coro era diaria.

En segundo lugar, el núcleo de los estudios existentes en el interior del Colegio fue durante todo este período la enseñanza de la gramática latina.

Junto a ésta, en tercer y más secundario lugar, la fuente anterior nos informa de que en torno a estas fechas, o poco más tarde, se estableció enseñanza de teología moral, cursada por espacio de tres años bajo la dirección de un presidente, con hora y media de aula diaria. Con ello, el Seminario preparaba a sus colegiales para la llamada "carrera breve" 30 .

Aprendizaje de la gramática latina y asistencia al coro, así pues, venían a llenar prácticamente las obligaciones de estudio de los colegiales, ocupando -diríamos que absorbiendo- buena parte de su discurrir cotidiano. Y en ambas materias el protagonismo del cabildo resultaba indiscutible.

El deber de asistencia diaria al coro resulta, a todas luces, de una interpretación abusiva del texto conciliar sobre la materia, porque en éste sólo se disponía que: "Cathedrali, et aliis loci Ecclesiis diebus festis inserviant". A la luz de este texto, los capitulares bien sabían de su exceso. Prueba de ello es que a lo largo del tiempo recurriesen a todo tipo de pretextos que les justificasen, que convirtiesen el hecho en costumbre, y la costumbre en disciplina particular (patronazgo en la fundación, pretendida conmutación por el fundador del servicio en las fiestas a las otras iglesias por el diario a la catedral...) Por una u otra razón, el caso es que tan dramático e interesado equívoco fue tomando cuerpo hasta tal punto que, mediado ya el siglo XVIII, corría en el ánimo de los miembros del Cabildo que Dávila había fundado para ellos, casi como merced especial: "el Colegio Seminario para el servicio diario de la Iglesia, y para el mayor aumento del divino culto" 31 . Y no es menos cierto que un hombre de carácter tan fuerte como el cardenal Belluga -primer obispo de Cartagena en el siglo XVIII- no tuvo más remedio cuando quiso reintegrar el Seminario fulgentino a las originales obligaciones tridentinas, que crear un Seminario (el de San Leandro) de infantes de coro específicamente dedicado a estos menesteres, cediéndolo por entero al control capitular.

En cuanto a la enseñanza de la gramática, el asunto resulta igualmente revelador -o quizá más todavía, dada su mayor trascendencia social- del peso del cabildo sobre el Seminario. Desde tiempo antes, existía en la catedral una Maestrescolía dotada en principio por una prebenda no colativa, la de Preceptoría, que en 1543 fue renunciada por el Maestrescuela ${ }^{32}$. Desde ese momento, el cabildo pasó a administrar directamente la

30 Esto nos permite pensar que efectivamente el tiempo de permanencia en el Seminario rondaría los seis años como mínimo (tres para gramática y tres para teología moral).

31 Francisco LOPEZ OLIVER, Al Ilustrísimo Señor Deán y Cabildo de la Santa Iglesia de Cartagena, el Dr. D...., su Capitular y menor capellán, Valencia, Viuda de Antonio Bordazar, 1749, p. 16.

32 La causa más plausible de este hecho reside en que el Maestrescuela no debía recibir ningún beneficio económico (e incluso pudo tener pérdidas), al tener que pagar a los preceptores que se encargaban efectivamente de la enseñanza. 
Preceptoría, y en consecuencia, a nombrar y pagar a los preceptores de la cátedra de gramática y retórica de la catedral en lugar de hacerlo -como hasta entonces- el Maestrescuela. En esas circunstancias vino a producirse la fundación del Seminario, y a decidirse la "aplicación e incorporación" de dicha cátedra: "para que de aquí en adelante se haya de leer, y lea en el Aposento de dicho Colegio Seminario; y para estipendio del regente de dicha Cáthedra señalaban, y señalaron, aplicaban, e aplicaron el anexo, y parte de la Maestrescolía de dicha Santa Iglesia" "33. La duda surge de inmediato: ¿se aplicaban al Seminario las rentas, o sólo la enseñanza efectiva?. Nuestra respuesta aquí no será la de dar una solución jurídica al problema planteado, sino la de describir cómo fue aplicada la decisión inicial durante el siglo XVII. En este sentido, lo único cierto es que el cabildo siguió administrando y controlando directamente tanto la renta como el nombramiento y pago de los preceptores hasta bien entrado el Setecientos ${ }^{34}$. De esta forma, el cabildo se encontró con un arma más en su poder para el control del Seminario, en este caso de sus principales estudios. Arma de cierta trascendencia social, como hemos avanzado, puesto que a las aulas de gramática del Seminario (regentadas por hombres como el humanista Francisco Cascales) no sólo asistieron los colegiales fulgentinos, sino también estudiantes externos.

Dicho esto, queda tan sólo pergeñar algunas notas sobre la organización y contenido de estas enseñanzas. En este terreno, no cabe esperar tampoco sorpresas en relación con lo que fueron los estudios de Gramática durante el Barroco: lección y explicación del texto de Nebrija, división de los estudiantes en dos o tres clases (mayores, medianos y menores) asistidas por el catedrático y los correspondientes repetidores, constantemente agobiados por problemas en el cobro de sus salarios que les conducían al desinterés, al absentismo, y a frecuentes choques con su patrón, el cabildo.

En cualquier caso, y a la vista de cuanto acabamos de decir, la historia de esta cátedra de gramática bien podría ser escrita con independencia de la del Colegio fulgentino ${ }^{35}$.

Por tanto, el Barroco alienta por doquier dentro del Seminario. En lo institucional -lo hemos visto profusamente-con la rigidez jerárquica y la dependencia capitular, trasunto esta última (puesta en relación con unos débiles, efímeros, y poco interesados obispos) de la dimensión político-social del Barroco, en el que las oligarquías locales disfrutan del control de los resortes de las esferas locales y regionales de poder.

Y en lo cultural. Aquí, por una parte, hemos de tener en cuenta la proyección casi exclusiva del Seminario hacia la enseñanza de la gramática latina. En esto se diferencia de la

33 Vid. F. LOPEZ OLIVER, op. cit., pp. 13-15, y Autos, fol. 88 recto.

34 De hecho, no fue infrecuente que las rentas de la Preceptoría no resultasen suficientes para mantener la cátedra. Supliendo en los momentos de déficit, el cabildo venía a crear así un argumento más en favor de su propia interpretación sobre el decreto de incorporación de ésta al Seminario, en el sentido de no haber constituído más que un simple traslado de emplazamiento, de la catedral al Seminario. Durante el siglo XVIII (pontificado de Roxas Contreras), el obispo logró finalmente que tanto la cátedra como la dotación de la Preceptoría fuesen sustraidas al cabildo e incorporadas de pleno derecho al Seminario, siguiendo el espíritu de los decretos tridentinos.

35 Estos datos, en los mencionados Autos, y obra de López Oliver, cit.. 
mayor parte de los Colegios, cuya principal vocación era universitaria. Pero en relación con esto, hemos de recuperar -para concluir- otras razones de fondo que también hemos ido mencionando. Nos referimos al concepto mismo que en esta época se tiene del sacerdote y del clero diocesano. En un esquema de los saberes profundamente jerarquizado, la teología y el derecho (con sus profesionales) ocupan la cúspide de los conocimientos, de la Universidad y del estatus social. Al sacerdote se le pide mucho menos (y por tanto se le pide mucho menos al Seminario que al Colegio universitario): que reconozca a sus superiores naturales y que sirva ante todo de correa de transmisión del dogma teológico y como agente de control social. De ahí la falta de preocupación, la ausencia o pobreza de enseñanzas teológicas más allá de las esenciales y de -sobre todo- las morales. De ahí la insistencia en la formación en la virtud ejemplar. De ahí, en suma, la ordenación de la vida cotidiana que hemos ido analizando durante este trabajo. De tal forma, las exigencias de la crisis barroca (la necesidad de controlar a la masa social) van unidas a la difusión de una religiosidad donde también predomina lo exterior, la norma y lo no racionalizado sobre planteamientos de mayor calado individual. Y también, a la falta de una auténtica pastoral, de la que el sacerdote del Barroco está casi ayuno. 